Results Correlation with ACQ-5 was obtained for the Hildebrandt index $(r=0,45 \mathrm{p}=0,0003)$, the respiratory rate $(\mathrm{r}=-$ $0,27, \mathrm{p}=0,032)$ and the relative pulse index $(\mathrm{r}=0.40$, $\mathrm{p}=0,0012)$. The association of Kerdo index with ACT-C test values $(r=-0,32, p=0,045)$ was established. In the group of patients with no BA control the Hildebrandt index was statistically significantly higher than in patients with control of the disease. In children with uncontrolled asthma it was 5,23 $\pm 0,25$ units that exceeds normal values and may reflect a mismatch in the work of cardiovascular and respiratory systems.

Conclusion The interrelation of changes of vegetative regulation and the level of control of bronchial asthma in children is established, as well as the mismatch of the functioning of the cardiovascular and respiratory systems in children with uncontrolled asthma.

\section{P21 MODERN TRENDS IN THE HEALTH STATUS OF THE CHILDREN'S POPULATION OF UKRAINE}

${ }^{1}$ Oleksandr Volosovets*, Sergii Kryvopustov ${ }^{2}$, Tetiana Volosovets ${ }^{3}$, Oleksandr Abaturov ${ }^{4}$ Tetyana Kryuchko ${ }^{5}$, Galyna Beketova ${ }^{3}$, Yuriy Bolbot ${ }^{6}$. ${ }^{1}$ Bogomolets National Medical University, Kyiv, Ukraine; ${ }^{2}$ Bogomolets National Medical University, Kyiv, Ukraine; ${ }^{3}$ Shupyk National Medical Academy of Postgraduate Education, Kyiv, Ukraine; ${ }^{4}$ Dnipropetrovsk Medical Academy of Health Ministry of Ukraine, Dnipro, Ukraine; ${ }^{5}$ Ukrainian Medical Stomatological Academy, Poltava, Ukraine; ${ }^{6}$ Dnipropetrovsk Medical Academy of Health Ministry of Ukraine, Kyiv, Ukraine

\subsection{6/archdischild-2019-epa.377}

Introduction An analysis of the morbidity and prevalence of diseases among the children's population of Ukraine, the level of infant mortality over the past 23 years suggests that they remain significantly higher than the average European indicators.

Objective Our objective was to analyze of the morbidity and prevalence of diseases among the children's population of Ukraine.

Materials and methods We have performed statistical analysis of the morbidity and prevalence of childhood illnesses and its significant differences in the regions of Ukraine.

Results The birth rate in 2017 is 364,000 children and is twice as low as the mortality rate of the entire population. The prevalence of childhood diseases over the past 23 years has increased by $41 \%$. If in 1994 it was 1253.0 per 1000 children, in 2017 it was 1748.0 per 1000 children of the corresponding age. The morbidity of childhood diseases also increased by $36 \%$, from 967.0 to 1292.0 per 1000 children, respectively.

The first place among the diseases were respiratory diseases in children, mainly due to acute respiratory infections and pneumonia. The indexes of dental diseases and pathology of nervous system and eye have increased moderately. The situation is aggravated by the decrease in the number of pediatricians in the country to 7.9 thousand, which reduces the availability of medical care, especially in rural areas.

Conclusions The negative dynamics of the morbidity and prevalence of childhood illnesses and its significant differences in the regions of Ukraine shows that this is primarily due to social, environmental and economic factors. Undoubtedly, the ongoing military conflict in the East of Ukraine is exacerbating the situation, which has led to more than 1.5 million refugees, including more than 200,000 children, who need constant and in-depth medical and social assistance. This indicates the need for constant attention to pediatric health care at the national level, taking into account the positive experience of the countries of the European Union.

\section{P22 THE EFFECTS OF STORAGE METHOD, TEMPERATURE AND EXTRACTION KITS ON THE HUMAN MILK MICROBIOTA}

${ }^{1,2}$ Katríona Lyons, ${ }^{1,3}$ Fiona Fouhy, ${ }^{4}$ Carol-Anne O' Shea, ${ }^{4} \mathrm{C}$ Anthony Ryan, ${ }^{3,5} \mathrm{R}$ Paul Ross, ${ }^{6}$ Alan Kelly, ${ }^{1,3}$ Catherine Stanton*. ${ }^{1}$ Teagasc Food Research Centre, Fermoy, Co. Cork, Ireland; ${ }^{2}$ School of Microbiology, University College Cork, Cork, Ireland; ${ }^{3}$ APC Microbiome Institute, University College Cork, Cork, Ireland; ${ }^{4}$ Cork University Maternity Hospital, Cork, Ireland; ${ }^{5}$ College of Science, Engineering and Food Science, University College Cork, Cork, Ireland; ${ }^{6}$ The School of Food and Nutritional Sciences, University College Cork, Cork, Ireland

10.1136/archdischild-2019-epa.378

Human breast milk is the optimum feeding regime for new born infants. In terms of composition, breast milk contains the required nutrients and bioactive compounds (e.g. oligosaccharides, lactoferrin, secretory antibodies, immune cells, CD14, regulatory cytokines) to support the growth and immunity of the developing infant. Until recently breast milk was considered to be a sterile fluid, however, advances in research has revealed that breast milk provides home to an array of bacterial species, which may provide various health benefits such as promoting gut colonisation, defence against pathogens and maturation of the immune system, an essential aspect of infant health.

Next generation sequencing has enabled detailed insights into the complex microbial ecosystem of breast milk, however authenticity of the microbiome is subject to many factors such as sample collection, suitable storage and extraction method of the biological sample. While cold storage $\left(4^{\circ} \mathrm{C}\right)$ immediately after sample collection until DNA extraction is optimal, other storage conditions need to be investigated for their efficacy when this option is not feasible. This study aims to investigate how different storage methods, temperatures additives and extraction techniques influence the human milk microbiome. Overall, $16 \mathrm{~S}$ compositional sequencing analysis revealed no significant differences from either fresh or frozen samples.

\section{P23 DETERMINANTS OF GAS EXCHANGE IN SMOKING AND NONSMOKING TEENAGERS DURING A STANDARDIZED SUBMAXIMAL TREADMILL TEST}

Stoilka Mandadzhieva*, Blagoi Marinov, Stefan Kostianev. Medical University of Plovdiv, Plovdiv, Bulgaria

\subsection{6/archdischild-2019-epa.379}

Introduction Assessment of physical capacity in the pediatric population has always been a major issue in developmental exercise physiology. It may be influenced by a number of factors, e.g. genetic endowment, developmental rate, body composition, and habitual physical activity. The adverse effects of smoking on the parameters and maximal effort during standardized submaximal treadmill test is not well known. 
Purpose The aim of the present study was to evaluate the determinants of gas exchange in smoking and nonsmoking teenagers during an incremental exercise test.

Materials and Methods One hundred and fifty healthy Bulgarian school children in the age span $15-17$ years took part in the study. All participants completed anthropometric measurements - standing height, weight and BMI and a questionnaire about smoking habits. The studied group performed an incremental exercise test on a treadmill following a modified Balke protocol.

Results Near $90 \%$ of participating teenagers completed the exercise test to the end. Boys showed significantly higher values of oxygen consumption on different levels of the test and maximal oxygen consumption $-\mathrm{VO}_{2}$ peak mL.min-1 $=2287$ \pm 337 vs. $1702 \pm 278 ; \mathrm{p}<0.001$. In the studied population, smokers had slightly lower values without a significant difference $-\mathrm{VO}_{2}$ peak mL.min- $1=1777 \pm 288$ vs. $1851 \pm 417$; NS. $\mathrm{VO}_{2}$ increases with age and correlated best with weight $(\mathrm{R}=0.83)$ and height $(\mathrm{R}=0.65)$ but less with BMI $(\mathrm{R}=0.59)$. Ventilatory equivalents for $\mathrm{O}_{2}$ and $\mathrm{CO}_{2}\left(\mathrm{~V}_{\mathrm{E}} / \mathrm{VO}_{2}, \mathrm{~V}_{\mathrm{E}} / \mathrm{VCO}_{2}\right)$ decline with age. Girls in comparison with the boys had greater fatigue perception (Borg scale) during the incremental test.

Conclusions The anthropometric parameters were the best determinants of physical capacity in teenagers. Smokers showed slightly lower but not significant values for $\mathrm{VO}_{2}$ peak. Boys had significantly higher values for $\mathrm{VO}_{2}$ peak compared with girls.

\section{P24 THE MAIN VIOLATIONS OF THE FUNCTIONS IN THE STATE OF HEALTH OF CHILDREN WITH DISABILITIES IN THE CITY CHILDREN'S POLYCLINIC}

\begin{abstract}
1,2Konstantin Shapjvalov, ${ }^{1}$ Larisa Shapovalova*, ${ }^{2}$ Nina Makarova, ${ }^{2}$ Galina Pokhodyaeva, ${ }^{2}$ Marina Zaboeva, ${ }^{2}$ Olga Markova. ${ }^{1}$ State Education Agency of Additional Professional Education of Republic of Komi 'Komi Republican Institute for Development of Education', Syktywkar, Russian Federation; 'State Budget Agency of Health of the Republic of Komi' Syktyvkar children's clinic [3]', Syktyvkar, Russian Federation
\end{abstract}

\subsection{6/archdischild-2019-epa.380}

Indicators of major impairments in the health status of children with disabilities are used as a daily statistical tool for objectifying the process of rehabilitating patients and identifying the strengths and facilities of a medical institution for the successful implementation of an individual program of rehabilitation/habilitation of a disabled person.

The analysis of the main violations of functions in the state of 1611 disabled children of the State Budget Agency of Health of Republic of Komi ' Syktyvkar children`s clinic $\square 3$ ' was conducted on the basis of medical documentation in 2011-2018.

Seven major violations of functions in the state of health of children with disabilities were identified: 1) Mental, of which perception, attention, memory, thinking, intelligence, consciousness, behavior, psychomotor functions, and other functions; 2) Language and speech, of which speech disorders (rhinolalia, dysarthria, alalia, aphasia), writing disorders (dysgraphy, dyslexia), disorders of verbal and non-verbal speech, voice disorders, and other violations of language and speech functions; 3) Sensory, of which sight, hearing, smell, touch, tactile, pain, temperature and other types of sensitivity; 4)
Statodynamic, including violations of the motor functions of the head, motor functions of the body, motor functions of the limbs, statics, coordination of movements; 5) Organs and systems, including blood circulation, respiration, digestion, excretion, blood formation, metabolism and energy, internal secretion, immunity; 6) Violations caused by physical deformity, of which lead to external deformity (deformation of the face, head, torso, limbs), abnormal digestive, urinary, respiratory tracts, violation of body size; 7) General and generalized.

The number of disabled children in the city children's clinic in 2011-2018 increased in absolute terms by 95 people with a growth rate of $157.23 \%$; the incidence of patients with disabilities increased 1.34 times to 159.92 per 10,000 contingent of children and adolescents.

According to the specific weight, among the main disorders in the state of children's health were: statodynamic - 35.34 $\pm 3.11 \%$ over the pathology of organs and systems 28.47 $\pm 2.93 \%$, mental $16.62 \pm 2.41 \%$, sensory $13.10 \pm 2.19 \%$, language and speech $5.49 \pm 1.48 \%$ (all p<0.001), general and generalized $0.56 \pm 0.49 \%, \mathrm{t}=1.143$ and disorders due to physical deformities $0.42 \pm 0,42 \%, t=1,000$.

With a total disability rate of 159.92 per 10,000 patient populations, it was divided between 7 main disorders of the body's functions: static-dynamic - 55.76; organs and systems 43.50; psychic - 34.31 ; sensory - 16.54 ; language and speech - 8.58; general and generalized - 0.61 and disorders due to physical deformities - 0.61 per 10,000 patients.

\section{P25 IMPLEMENTATION OF PREDICTION OF SOCIAL RISK OF ISCHEMIC STROKE ON CHILDREN'S POPULATION OF UKRAINE}

AA Volosovets*, IS Zozulya. Shupyk National Medical Academy of Postgraduate Education, Kyiv, Ukraine

\subsection{6/archdischild-2019-epa.381}

Introduction Acute ischemic stroke is one of the most often causes of disability and death worldwide. Unfortunately it is widespread even among young patients - prevalence of stroke among children reaches from 2 to 6 per 100,000 children. The number of etiological factors that may lead to stroke in children is very high, but social factors are making significant contribution to the occurrence of stroke.

Objective Our objective is to study the spectrum of social risk factors, their impact on the incidence of cerebral ischemic stroke and possible correlation with social risk factors in children's population of Ukraine.

Materials and methods We have examined 140 grown-up patients with ischemic stroke (average age - 65,2 \pm 8,7 years) using clinical and instrumental methods, laboratory examination and detailed clinical and anamnestic survey. 45 young patients with stroke (average age $-9,3 \pm 3,8$ years) were included retrospectively in research for comparison of social risk factors of stroke.

Results Among known social predictors of development of cerebral ischemia we discover 7 risk factors (sleep disturbance, excessive stress, abnormal nocturnal activity, long-term work with monitors, reduced physical activity, irregular meals, severe smoke and alcohol addiction) with higher incidence and use them to evaluate risk of possible cerebral stroke with help of specialized social risk of stroke scale. 